\title{
Acute Effect of Resistance Exercise on Mucociliary Clearance in Active Smokers
}

\author{
Alessandra Mayumi Marques Masuda, ${ }^{(0)}$ Iara Buriola Trevisan, ${ }^{(1)}$ Tamara dos Santos Gouveia, (D) Guilherme \\ Yassuyuki Tacao, ${ }^{(0)}$ Ercy Mara Cipulo Ramos, ${ }^{[0}$ Dionei Ramos ${ }^{(1)}$ \\ Universidade Estadual Paulista Júlio de Mesquita Filho (UNESP), Presidente Prudente, SP - Brazil
}

\section{Abstract}

Background: Nasal mucociliary clearance (NMC) responds to autonomic activity through exercise. However, there is a gap in the literature on how NMC responds to resistance exercise.

Objective: To evaluate the acute effects of resistance tube exercise on NMC and the autonomic nervous system in smokers.

Methods: Clinical trial was performed with 18 individuals. Personal, anthropometric, and smoking history data were collected, and a pulmonary function test was performed by spirometry. The fatigue resistance test was performed in order to obtain the number of repetitions for the prescription of exercise. Heart rate variability was captured using a monitor. Subsequently, the exhaled carbon monoxide (exCO) was measured and a saccharin transit test (STT) was performed for NMC.

Results: The non-smoking group presented a significant decrease of 4.0 \pm 3.2 minutes in STT after P1 ( $\mathrm{p}=0.021$ ). Regarding HRV, the smoking group presented a significant decrease of mean RR $(-90.3 \pm 53.0 ; p=0.011), S D N N$ $(-560.0 \pm 1333.2 ; \mathrm{p}=0.008), \operatorname{RMSSD}(-13.6 \pm 10.5 ; \mathrm{p}=0.011), \mathrm{LFms}^{2}(-567.3 \pm 836.1 ; \mathrm{p}=0.008), \mathrm{HFms}^{2}(-223.8 \pm 231.8 ; \mathrm{p}=0.008)$, SD1 (-9.7 $\pm 7.4 ; p=0.011)$ and SD2 (-20.7 $\pm 17.0 ; p=0.008)$, and an increase of mean HR $(10.2 \pm 5.9 ; p=0.011)$ after P2. In the non-smoking group, a significant decrease was observed in the mean RR $(-67.1 \pm 70.7 ; \mathrm{p}=0.038), \mathrm{SDNN}(-16.8 \pm 15.0$; $\mathrm{p}=0.015), \operatorname{RMSSD}(-12.3 \pm 14.7 ; \mathrm{p}=0.011), \mathrm{LFms}^{2}$ (-831.2 $\left.\pm 1347.5 ; \mathrm{p}=0.015\right), \mathrm{SD} 1$ (-8.7 $\left.\pm 10.4 ; \mathrm{p}=0.011\right)$, and SD2 (-22.0 $\pm 19.1 ;$ $\mathrm{p}=0.015)$, while an increase in $\operatorname{HR}(7.1 \pm 7.3 ; \mathrm{p}=0.028)$ was found after P1.

Conclusions: The intensity of the resistance exercise applied to the patient was not enough to promote changes in smokers. By contrast, in non-smokers, the same intensity of exercise was effective in promoting alterations in the NMC and autonomic activity. (Int J Cardiovasc Sci. 2021; 34(2):223-230)

Keywords: Smoking; Mucociliary Clearance; Autonomic Nervous System; Resistance Training.

\section{Introduction}

Nasal mucociliary clearance (NMC) is the interaction between the cilia and the mucus layer of the respiratory system, and it is influenced by cigarette smoking and exercise. $^{1-6}$

Chronic exposure to cigarette smoking induces oxidative stress and leads to changes in the respiratory epithelium, such as a decline in the frequency of the ciliary beat and increasing mucus hypersecretion, increasing the vulnerability to respiratory infections. Previous studies showed that NMC time is longer for smokers when compared to that for non-smokers due to the activation of nicotinic receptors ${ }^{1-3}$ and autonomic nervous system dysfunction. ${ }^{7}$ In addition to harmful agents of cigarette smoking, NMC responds through physical exercise..$^{5-9}$

The impact of exercise induces an increase in the autonomic nervous system activity, a release of adrenergic mediators, and an increase in the ventilation and respiratory rate, which causes an increase in the NMC. ${ }^{10}$ However, concerning the type and duration of physical exercise on mucociliary transport, studies in 
the literature have presented contradictory evidence in different populations.

Leite et al., ${ }^{8}$ conducted a study with the effect of 12 weeks of aerobic training on autonomic modulation and NMC in subjects with COPD, reaching the conclusion of an increase in parasympathetic activity, a reduction in sympathetic activity in autonomic modulation, but no significant influence in NMC. Silva et al., ${ }^{9}$ evaluated the effects of 12 weeks of resistance training and reported significant improvement in NMC in COPD.

In response to the acute effect, the study of Ramos et al., ${ }^{5}$ reported an increase in NMC after the stimulus of aerobic exercise, and this response was correlated with sympathetic activity in smokers. However, this behavior is not yet known in resistance exercise in smokers.

Resistance training is generally carried out on expensive machines and devices. An alternative method is the use of such devices as the elastic tube, a portable and inexpensive instrument that has shown results for muscle activation, strength gain, and quality of life, equivalent to conventional training, ${ }^{9-12}$ but still with no NMC results in smokers. Therefore, the goal of the present study was to evaluate the acute effects of resistance tube exercise on the NMC and autonomic nervous system in smokers and to observe the responses found in isolated and smoking-associated exercise.

\section{Methods}

A clinical trial was conducted with 30 to 50-yearold smokers and non-smokers, regardless of gender, recruited through media and advertisements in newspapers. Individuals with pre-existing chronic diseases that prevent physical exercise, who have undergone surgery or suffered nasal trauma, who report a history of alcoholism and/or illicit drug use, who present respiratory infections, who are in the process of quitting smoking, who practice regular physical exercise at least 20 minutes a day, three days a week for six months, and who did not complete all of the study protocols were excluded from this study.

Thirty-five individuals were recruited for this study, 25 in the smoking group and 10 in the non-smoking group. However, after applying the exclusion criteria, 9 smokers were included (11 were over 50 years of age and 5 did not attend all of the evaluation days) and 9 non-smokers (1 did not attend all of the evaluation days).
The protocol was performed on three non-consecutive days (48-h interval between days), in the mornings, in rooms in which the temperature $\left(22.4 \pm 2.0^{\circ} \mathrm{C}\right)$ and relative humidity $(51.4 \pm 7.9 \%)$ were controlled through a thermometerhygrometer (Incoterm, model 766.02.0.00). Each day, subjects were asked to eat a light meal two hours before the evaluations and abstain from alcohol, caffeine, smoking, and vigorous exercise for 12 hours before the evaluations. Individuals were previously informed about the research objectives and procedures and, after agreement, signed an informed consent form. The project was approved by the Institutional Review Board (CAAE: 56.405.316.1.0000.5-402).

On the first day of the protocol, personal data, anthropometric (weight, height, and body mass index (BMI)) and smoking history (years of smoking, number of cigarettes/day and packs/year), as well as the level of nicotine addiction assessed by the Fagerstrom test $t^{12}$ were collected. A pulmonary function test was then performed by spirometry, with normality values relative to the Brazilian population, using a portable MIR Spirobank spirometer version 3.6. ${ }^{13,14}$ Finally, fatigue resistance test was performed in order to obtain the number of repetitions for the individual prescription of the resistance exercise session.

The fatigue resistance test consists of pushing the individual to fatigue within $40-75$ seconds after the beginning of each movement execution (knee extension and flexion, shoulder abduction and flexion, and elbow flexion). The initial load used to perform the test was determined by the therapist's perception. When the maximum time of 75 seconds is exceeded, the load was increased, whereas if the fatigue occurred before 40 seconds, the load was reduced. ${ }^{15}$

A maximum of five attempts were made for each movement, where, in each attempt, the individual should perform as many repetitions as he/she can, as quickly as possible, and maintain the pace of movement from the beginning of the test. The test was interrupted by: fatigue, significant reductions in the amplitude or speed of movement, and muscle compensations.

Elastic tubing was used for both groups (smoking and non-smoking). Different tubes with progressive resistance were used in such a way that the higher the reference number, the higher the resistance of the tube (\#200, \#201, \#202, \#203, and \#204, Lemgruber@, Brazil). ${ }^{16}$

The number of repetitions achieved in these 40 seconds was used as a reference to calculate the number of repetitions proportional to 20 seconds. From the 
definition of the number of repetitions, the training was performed in 2 sets of 20 seconds each, with an interval of 2 minutes between them. The abduction and shoulder flexion and elbow flexion movements were performed in an orthostatic position (Figure 1A, B, and C). The knee extension was performed sitting on a chair in the patterns of $72 \mathrm{~cm}$ in height and $52 \mathrm{~cm}$ in width (Figure $1 \mathrm{E})$. Knee flexion, however, was performed in an orthostatic position, in front of the same chair (Figure 1D). One end of the tube was attached to an iron bar and the other end to the member to be worked. ${ }^{11}$

The smoking group performed two distinct protocols: (1) a resistance tube exercise session performed in 2 sets of 20 seconds each (P1) and (2) a resistance tube exercise session performed in 2 sets of 20 seconds, each immediately followed by smoking two cigarettes for 20 minutes (P2). The non-smoking group performed only the P1 protocol.

On exercise days (second and third day), participants initially remained at rest, in a sitting position, for 20 minutes for the collection of baseline heart rate variability (HRV). After, the exhaled carbon monoxide (exCO) was collected and a saccharin transit test (STT) was performed in order to collect the nasal MC at rest. These proceedings were repeated immediately after finishing protocols P1 and P2 (effect acute - less than 5 minutes).
Beat-to-beat HRV was captured using a heart rate monitor (Polar S810i, Finland). ${ }^{17}$ A total of 256 consecutive RR intervals were selected at the time the participant reported the STT saccharin taste. In other words, 128 beats before and 128 beats from the STT on were filtered at the beginning (baseline) and at the end (acute effect) of the day of each protocol. ${ }^{5}$ The selected piece was subjected to digital (and complemented by manual) filtering by the Polar Precision Performance SW software (version 4.01.029) for the elimination of premature ectopic beats and artifacts, and only a series with more than $95 \%$ of sinus rhythm were included in the study. The Kubios software (Biosignal and Medical Image Analysis Group, Department of Physics, University of Kuopio, Kuopio, Finland $)^{18}$ was used to calculate the HRV indexes.

The following indexes in the time domain were analyzed: mean interval between adjacent normal heartbeats (RR intervals), the square root of the sum of successive differences between RR intervals (RMSSD, expressed in ms - parasympathetic activity), and the SD of all normal RR intervals (SDNN, expressed in ms - global variability). In the frequency domain, low (LF, $0.04-015 \mathrm{~Hz}$, global variability) and high (HF, 0.15 $0.40 \mathrm{~Hz}$, parasympathetic activity) frequency spectral components were analyzed in normalized units (un), squared milliseconds (ms2), and the ratio between

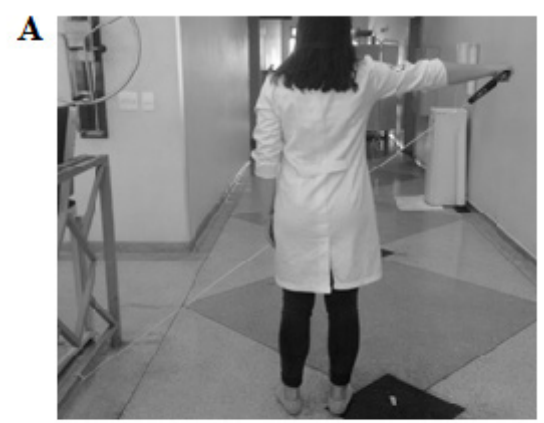

B

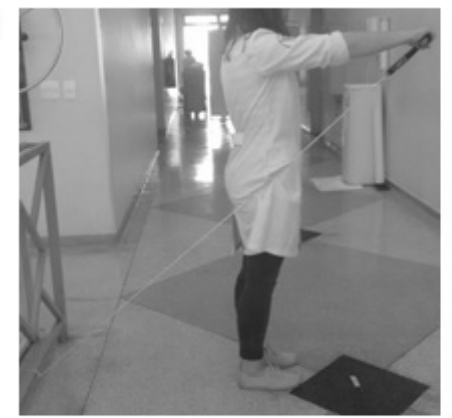

C

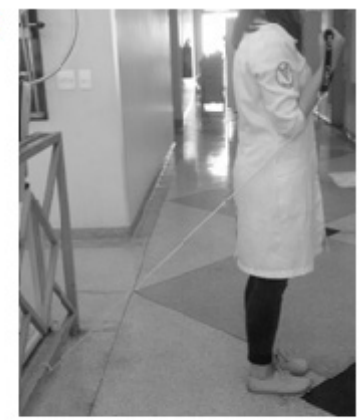

D

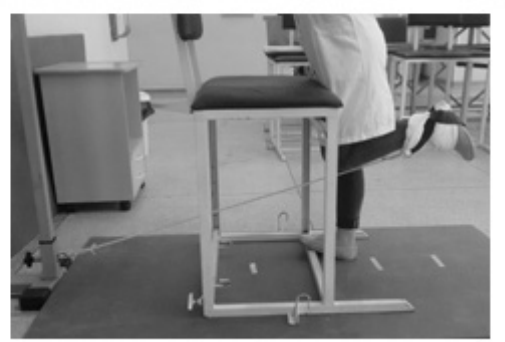

E

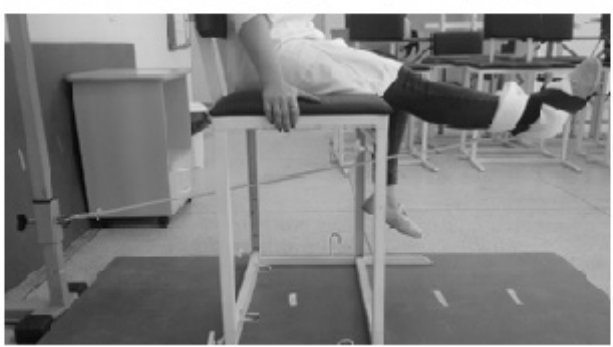

Figure 1 - Elastic tubing resistance exercise for abduction (A), shoulder flexion (B), elbow flexion (C), knee flexion (D) and extension (E). 
these components (LF/HF ratio). ${ }^{17,19,20}$ The frequency domain analysis was calculated using the Fast Fourier Transform algorithm. ${ }^{21}$

The Poincaré plot is a diagram in which each RR interval is plotted as a function of the next interval. Its analysis was performed by adjusting the figure ellipse formed by the attractor, from which the following indexes were calculated: SD1 (standard deviation of instantaneous beat-to-beat variability - vagal modulation) and SD2 (standard deviation of long-term continuous RR interval variability). ${ }^{17,19,20}$

exCO was collected by the monoximeter (Micro Medical Ltd., Rochester, Kent, United Kingdom), and data were expressed as parts per million (ppm) and carboxyhemoglobin ( $\mathrm{HbCO}$ ).

STT was performed according to previous studies. ${ }^{1-6,8,9}$ Approximately 250 micrograms of granulated sodium saccharin were applied, two centimeters inside the right nostril, and the time it has taken for the participant to identify a taste in the mouth was recorded before and after of the day of each protocol. When the taste was not identified within 60 minutes, the test was stopped.

Data analysis was performed using the statistical software SPSS 22.0. Data normality assumption was tested using the Shapiro-Wilk test, and the results were described as mean and standard deviation, except for variables with non-normal distribution, which were described as median and interquartile range (25-75). For intergroup analysis, the delta $(\Delta)$ was performed, that is, the final result was divided by the baseline moment and the values obtained were compared between the groups, using the Student's t-test for independent samples or the Mann Whitney test, depending on the normality of the data.

For the intragroup analysis, either the Student's t-test for dependent samples or the Wilcoxon test was used, depending on the normality of the data. The significance level used was $\mathrm{p}<0.05$.

\section{Results}

The smoking group consisted of nine subjects, $41.4 \pm 6.7$ years of age, BMI of $24.6 \pm 4.5 \mathrm{~kg} / \mathrm{m}^{2}, \mathrm{FEV}_{1} / \mathrm{FVC}$ ratio of $97.1 \pm 7.5 \%$, smoking on average $16.3 \pm 5.0$ cigarettes/day for $23.0 \pm 8.6$ years (19.3 \pm 9.1 packs/year), with a moderate dependence level (5.3 \pm 1.8 points). The non-smoker group consisted of nine subjects, $37.6 \pm 8.4$ years of age, BMI of $27.2 \pm 4.9 \mathrm{~kg} / \mathrm{m}^{2}$, and $\mathrm{FEV}_{1} / \mathrm{FVC}$ ratio of $105.0 \pm 9.4 \%$.
No significant difference was observed between the groups regarding the above characteristics and regarding the number of repetitions per series for each movement performed during resistance training with elastic tubes (Table 1).

Table 2 presents the STT, exCO, environment control, and HRV data.

Only the non-smoking group presented a significant average decrease of $4.0 \pm 3.2$ minutes in STT after P1 $(\mathrm{p}=0.021)$. The smoking group presented a significant decrease in exCO $(-2.3 \pm 3.0$ ppm; $\mathrm{p}=0.016)$ and $\mathrm{HbCO}$ $(-0.4 \pm 0.5 \% ; \mathrm{p}=0.016)$ in $\mathrm{P} 1$ and a significant increase in exCO (8.0 \pm 5.7 ppm; p=0.008) and $\mathrm{HbCO}(2.4 \pm 3.5 \%$; $\mathrm{p}=0.008)$ in $\mathrm{P} 2$.

Regarding HRV, the smoking group presented a significant decrease in mean RR $(-90.3 \pm 53.0 ; \mathrm{p}=0.011)$, SDNN (-560.0 $\pm 1333.2 ; \mathrm{p}=0.008)$, RMSSD $(-13.6 \pm 10.5$; $\mathrm{p}=0.011), \mathrm{LFms}^{2}(-567.3 \pm 836.1 \mathrm{p}=0.008), \mathrm{HFms}^{2}$ $(-223.8 \pm 231.8 ; \mathrm{p}=0.008), \mathrm{SD} 1(-9.7 \pm 7.4 ; \mathrm{p}=0.011)$, and SD2 (-20.7 $\pm 17.0 ; \mathrm{p}=0.008)$, as well as an increase in mean HR $(10.2 \pm 5.9 ; \mathrm{p}=0.011)$ only after P2. In the non-smoking group, a significant decrease was found in mean $R R$ (-67.1 $\pm 70.7 ; \mathrm{p}=0.038), \operatorname{SDNN}(-16.8 \pm 15.0 ; \mathrm{p}=0.015)$, RMSSD (-12.3 $\pm 14.7 ; \mathrm{p}=0.011), \mathrm{LFms}^{2}(-831.2 \pm 1347.5$; $\mathrm{p}=0.015)$, SD1 $(-8.7 \pm 10.4 ; \mathrm{p}=0.011)$, and SD2 $(-22.0 \pm 19.1$; $\mathrm{p}=0.015)$, as well as an increase in HR $(7.1 \pm 7.3 ; \mathrm{p}=0.028)$ after the P1 protocol.

In P1, a difference between the two groups was observed for the following variables: STT $(p=0.049)$, Mean HR $(p=0.015)$, and SD2 $(p=0.017)$. No significant difference in the temperature and relative humidity data were found in the intragroup and intergroup evaluation .

\section{Discussion}

In the present study, it was observed that the time of NMC and HRV of smokers did not change in response to isolated resistance tube exercises. However, after smoking-associated exercise, the same group showed significant changes in HRV, which may be explained by immediate smoking. In contrast, non-smokers showed a significant decrease in STT, suggesting an acceleration of NMC and changes in HRV.

Under basal conditions, smokers' STT was reduced if compared to the group of non-smokers, a result which proved to be similar to that reported in the literature. ${ }^{1,3}$ After the acute act of smoking, a decrease in STT was observed due to the acute response of NMC defense against the toxic 
Table 1 - Baseline characteristics of the study sample. Data expressed as mean and standard deviation

\begin{tabular}{|c|c|c|c|}
\hline Anthropometric variables & Smoking $(n=9)$ & Non-Smoking $(\mathrm{n}=9)$ & p-value \\
\hline $\operatorname{Sex}(F / M)$ & $6 / 3$ & $7 / 2$ & 1 \\
\hline Age (years) & $41.4 \pm 6.7$ & $37.6 \pm 8.4$ & 0.293 \\
\hline Weight (kg) & $68.7 \pm 16.0$ & $76.2 \pm 20.7$ & 0.399 \\
\hline Height (m) & $1.7 \pm 0.1$ & $1.7 \pm 0.1$ & 1 \\
\hline BMI $\left(\mathrm{kg} / \mathrm{m}^{2}\right)$ & $24.6 \pm 4.5$ & $27.2 \pm 4.9$ & 0.161 \\
\hline \multicolumn{4}{|l|}{ Smoking history } \\
\hline Cigarettes/day & $16.3 \pm 5.0$ & NA & \\
\hline Years of smoking & $23.0 \pm 8.6$ & NA & \\
\hline Packs/year & $19.3 \pm 9.1$ & NA & \\
\hline Fagerstrom & $5.3 \pm 1.8$ & NA & \\
\hline \multicolumn{4}{|l|}{ Spirometric variables } \\
\hline FVC (\% pred) & $99.0 \pm 15.1$ & $91.0 \pm 8.8$ & 0.188 \\
\hline $\mathrm{FEV}_{1}(\%$ pred $)$ & $96.0 \pm 15.4$ & $94.0 \pm 8.7$ & 0.739 \\
\hline $\mathrm{FEV}_{1} / \mathrm{FVC}(\%)$ & $97.1 \pm 7.5$ & $105.0 \pm 9.4$ & 0.066 \\
\hline $\mathrm{FEF}_{25-75 \%}(\%$ pred $)$ & $100.0 \pm 30.3$ & $113.2 \pm 32.7$ & 0.387 \\
\hline \multicolumn{4}{|c|}{ Number of repetitions per set } \\
\hline shoulder abduction & $25.6 \pm 6.4$ & $24.4 \pm 5.1$ & 0.690 \\
\hline shoulder flexion & $27.3 \pm 5.0$ & $25.7 \pm 6.1$ & 0.534 \\
\hline elbow flexion & $28.0 \pm 3.8$ & $28.6 \pm 5.5$ & 0.806 \\
\hline knee extension & $31.9 \pm 6.8$ & $31.8 \pm 5.7$ & 0.970 \\
\hline knee flexion & $30.3 \pm 5.6$ & $29.2 \pm 4.4$ & 0.644 \\
\hline
\end{tabular}

components of cigarettes and by the nicotine action that promotes sympathetic activation and, consequently, the acceleration of a ciliary beat. ${ }^{3,5,6}$

For isolated exercise, there was a decrease in STT in non-smokers. The mechanism by which exercise improves mucociliary transportability time is related to the stimulation of the autonomic nervous system. ${ }^{5,6}$ Increased exercise-induced ventilation stimulates the respiratory center, increasing vagal activity, which, in turn, increases mucus secretion. Moreover, by exercising, plasma catecholamine levels are elevated and stimulate sympathetic activity, accelerating the ciliary beat ${ }^{10,22}$ in aerobic $^{5}$ or resistance exercises. ${ }^{9}$
One of the hypotheses that isolation exercise had no effect on smokers' NMC may be related to a decrease in STT at baseline. Previous studies have shown that the chronic effect of smoking causes changes in HRV, with a predominantly sympathetic tone. ${ }^{23,24} \mathrm{NMC}$ is a complex system where the sympathovagal balance plays an important role in its functioning. 5,6

Regarding the HRV outcomes, it was observed that the smoking group showed changes in the parasympathetic system expressed by the RMSSD, HF, and SD1 indexes, in addition to other indices, such as SDNN, LF, and SD2 only in the protocol associated with smoking. A previous study corroborates the results and concluded that smoking has 


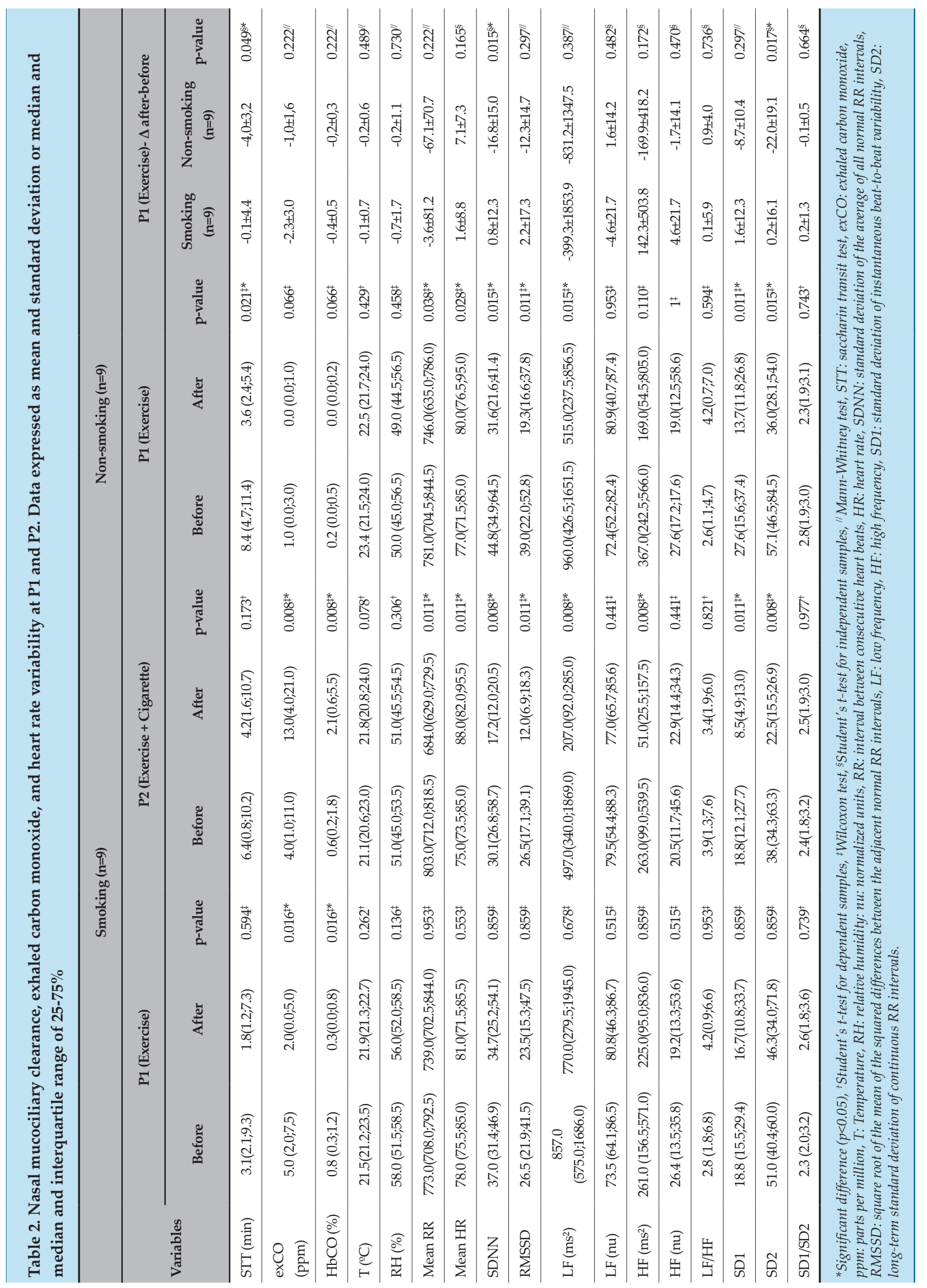


been associated with an increase in the sympathetic nervous system and a decrease in the parasympathetic nervous system. ${ }^{25}$

The sample was calculated based on the study conducted by Habesoglu et al., ${ }^{26}$ in which an index of STT was selected. The difference to be detected was 17.19 , and the SD was 12.41. The significance level for the sample calculation was $5 \%$, with a test power of $80 \%$ and a 2 -tailed hypothesis test. The value obtained from the sample calculation was 9 subjects per group.

The duration and intensity of light to moderate resistance tube exercise may have been another associated and limiting factor that was unable to increase sympathetic stimulation and, consequently, decrease transportability time in smokers. Other limiting factors of the study were the lack of heart rate variability analysis in isolated smoke to confirm the autonomic responses found. Thus, further research on the effects of resistance exercise at different intensities and compared to aerobic exercise are suggested in order to identify the effectiveness of this exercise modality, using elastic tubes, which are portable and inexpensive devices that provided the same effectiveness as conventional training with high-cost machines and devices in smokers' respiratory health.

\section{Conclusion}

In summary, the intensity of resistance exercise applied in the present study was not enough to promote alterations in the NMC or in the autonomic nervous system of smokers. However, in non-smokers, the same intensity of exercise was effective in causing

\section{References}

1. Xavier RF, Ramos D, Ito JT, Rodrigues FM, Bertolini GN, Macchione M, et al. Effects of cigarette smoking intensity on the mucociliary clearance of active smokers. Respiration. 2013;86(6):479-85.

2. Ramos EM, Toledo AC, Xavier RF, Fosco LC, Vieira RP, Ramos D, et al. Reversibility of impaired nasal mucociliary clearance in smokers following a smoking cessation programme. Respirology. 2011;16(5):84955.

3. Proença M, Xavier R, Ramos D, Cavalheri V, Pitta F, Ramos EM. Immediate and short term effects of smoking on nasal mucociliary clearance in smokers. Rev Port Pneumol. 2011;17(4):172-6.

4. Dulger S, Akdeniz O, Solmaz F, Dikiş OS, Yildiz T. Evaluation of nasal mucociliary clearance using saccharin test in smokers: A prospective study. Clin Respir J. 2018;12(4):1706-10.

5. Ramos EM, Vanderlei LC, Ito JT, Lima FF, Rodrigues FM, Manzano $\mathrm{BM}$, et al. Acute mucociliary clearance response to aerobic exercise. Respir Care. 2015;60(11):1575-84.
NMC acceleration and changes in the autonomic nervous system.

\section{Author contributions}

Conception and design of the research: Masuda AMM, Trevisan IB, Gouveia TS, Tacao GY, Ramos EMC, Ramos D. Acquisition of data: Masuda AMM, Trevisan IB, Gouveia TS, Tacao GY, Ramos EMC, Ramos D. Analysis and interpretation of the data: Masuda AMM, Trevisan IB, Gouveia TS, Tacao GY, Ramos EMC, Ramos D. Writing of the manuscript: Masuda AMM, Trevisan IB, Ramos EMC, Ramos D. Critical revision of the manuscript for intellectual content: Masuda AMM, Trevisan IB, Ramos EMC, Ramos D.

\section{Potential Conflict of Interest}

No potential conflict of interest relevant to this article was reported.

\section{Sources of Funding}

This study was funded by the São Paulo State Research Foundation (FAPESP; grant 2016/06454-1 and 2016/10721-5) and Coordination for the Improvement of Higher Education Personnel (CAPES).

\section{Study Association}

This article is part of the undergraduate thesis submitted by Alessandra Mayumi Marques Masuda, from Universidade Estadual Paulista Júlio de Mendonça Filho (Unesp), Campus Presidente Prudente.
6. Proença M, Pitta F, Kovelis D, Mantoani LC, Furlanetto KC, Zabatiero $\mathrm{J}$, et al. Mucociliary clearance and its relation with the level of physical activity in daily life in healthy smokers and nonsmokers. Rev Port Pneumol. 2012;18(5):233-8.

7. Manzano BM, Vanderlei LCM, Ramos EMC, Ramos D. Smoking implications on cardiac autonomic control. Arq Ciênc Saúde. 2010 Apr-Jun; 17(2): 97-101

8. Leite MR, Ramos EM, Kalva-Filho CA, Freire AP, de Alencar Silva BS, Nicolino J, et al. Effects of 12 weeks of aerobic training on autonomic modulation, mucociliary clearance, and aerobic parameters in patients with COPD. Int J Chron Obstruct Pulmon Dis. 2015;10:254957.

9. Silva BS, Ramos D, Bertolini GN, Freire AP, Leite MR, Camillo CA, et al. Ramos. Resistance exercise training improves mucociliary clearance in subjects with COPD: A randomized clinical trial. Pulmonol. 2019;25(6):340-7. 
10. Wolff RK, Dolovich MB, Obminski G, Newhouse MT. Effects of exercise and eucapnic hyperventilation on bronchial clearance in man. J Appl Physiol. 1977;43(1):46-50.

11. Ramos EM, Toledo-Arruda AC, Fosco LC, Bonfim R, Bertolini GN, Guarnier FA, et al. The effects of elastic tubing-based resistance training compared with conventional resistance training in patients with moderate chronic obstructive pulmonary disease: a randomized clinical trial. Clin Rehabil. 2014;28(11):1096-106.

12. Meneses-Gaya IC, Zuardi AW, Loureiro SR, Crippa JAS. As propriedades psicométricas do teste de fagerström para dependência de nicotina. J Bras Pneumol. 2009;35(1):73-82.

13. Miller MR, Hankinson J, Brusasco V, Burgos F, Casaburi R, Coates A, et al. Standardization of spirometry. Eur Respir J. 2005;26(2):319-38.

14. Duarte AA, Pereira CA, Rodrigues SC. Validation of new Brazilian predicted values for forced spirometry in Caucasians and comparison with predicted values obtained using other reference equations. J Bras Pneumol. 2007;33(5):527-35.

15. Lopes JS, Micheletti JK, Machado AF, Souto LR, Lima HP, Vanderlei FM, et al. Test-retest reliability of knee extensors endurance test with elastic resistance. PLoS One. 2018 Aug 31;13(8):e0203259.

16. Lima FF, Camillo CA, Reis EA, Job AE, Silva BS, Topalovic M, et al. Mechanical properties, safety and resistance values of Lemgruber((R)) elastic tubing. Braz J Phys Ther. 2018;23(1):41-7.

17. Vanderlei LC, Silva RA, Pastre CM, Azevedo FM, Godoy MF. Comparison of the Polar S810i monitor and the ECG for the analysis of heart rate variability in the time and frequency domains. Braz J Med Biol Res. 2008;41(10):854-9.

18. Tarvainen MP, Niskanen J-P, Lipponen JA, Ranta-Aho PO, Karjalainen PA. Kubios HRV - A software for advanced heartrate variability analysis. Berlin: Springer: In: 4th European Conference os the International
Federation for Medical and Biological Engineering. Berlin:Springer; 2008. p.1022-5.

19. Vanderlei LC, Pastre CM, Hoshi RA, Carvalho TD, Godoy MF. Noções básicas de variabilidade da frequência cardíaca e sua aplicabilidade clínica. Rev Bras Cir Cardiovasc. 2009;24(2):205-17.

20. Ferreira MT, Messias M, Vanderlei LC, Pastre CM. Caracterização do comportamento caótico da variabilidade da frequência cardíaca (VFC) em jovens saudáveis. TEMA Tend Mat Apl Comput. 2010;11(2):141-50.

21. Godoy MF, Takakura IT, Correa PR. Relevância da análise do comportamento dinâmico não linear (Teoria do Caos) como elemento prognóstico de morbidade e mortalidade em pacientes submetidos à cirurgia de revascularização miocárdica. Arq Ciênc Saúde. 2005; 12(4):167-71.

22. Mendonca GV, Pereira FD, Fernhall B. Effects of cigarette smoking on cardiac autonomic function during dynamic exercise. J Sports Sci. 2011;29(9):879-86.

23. Santos AP, Ramos D, Oliveira GM, Santos AA, Freire AP, Ito JT, et al Influence of Smoking Consumption and Nicotine Dependence Degree in Cardiac Autonomic Modulation. Arquivos Brasileiros de Cardiologia. 2016;106(6):510-8.

24. Middlekauff HR, Park J, Moheimani RS. Adverse effects of cigarette and noncigarette smoke exposure on the autonomic nervous system: mechanisms and implications for cardiovascular risk. J Am Coll Cardiol. 2014;64(16):1740-50.

25. Sumartiningsih S, Lin HF, Lin JC. Cigarette Smoking Blunts ExerciseInduced Heart Rate Response among Young Adult Male Smokers. Int J Environ Res Public Health. 2019;16(6):1032.

26. Habesoglu M, Demir K, Yumusakhuylu AC, Yilmaz AS, Oysu C. Does Passive Smoking Have an Effect on Nasal Mucociliary Clearance? Otolaryngol Head Neck Surg. 2014; 147(1): 151-6. 